\section{Case Reports in Neurology}

\title{
A Challenging Case: Endovascular Treatment in a Patient with Large Ischemic Core and Dramatic Recovery
}

\author{
Trung Quoc Nguyen ${ }^{a}$ Tinh Quang Dang ${ }^{b}$ Hoang Thi Phan ${ }^{a, c, d}$ \\ Thang Huy Nguyen ${ }^{\text {a, }}$ \\ a115 People's Hospital, Ho Chi Minh City, Vietnam; bHo Chi Minh City Medicine and \\ Pharmacy University, Ho Chi Minh City, Vietnam; 'Menzies Institute for Medical Research, \\ University of Tasmania, Hobart, TAS, Australia; dPham Ngoc Thach University of Medicine, \\ Ho Chi Minh City, Vietnam
}

\section{Keywords}

Stroke $\cdot$ Large core $\cdot$ Thrombectomy $\cdot$ Dramatic recovery $\cdot$ Challenging case

\begin{abstract}
Uncertainty exists over the efficacy and safety of endovascular treatment in patients with large ischemic cores in anterior circulation. Several trials have shown some potential benefits in selected patients despite their late presentation. In particular, perfusion imaging modalities equipped with automatic software has been proven useful in identifying patients with large ischemic cores that are at risk of infarct core expansion, meaning that this specific patient group could still benefit from reperfusion treatment. We reported a case of late-presenting and progressing acute ischemic stroke who was selected by perfusion imaging with RAPID software and successfully underwent endovascular thrombectomy. On admission, her National Institutes of Health Stroke Scale (NIHSS) score was 7. Computed tomography angiography showed complete occlusion of the proximal right middle cerebral artery. Subsequent advanced perfusion imaging with automatic software showed that the ischemic core was $88 \mathrm{~mL}, \mathrm{~T}_{\max }$ $>6 \mathrm{~s}$ volume was $131 \mathrm{~mL}$, and mismatch volume was $43 \mathrm{~mL}$. She was rapidly transferred to the Cath lab for thrombectomy with a stent retriever. Her NIHSS score was 15 before the
\end{abstract}




\section{Case Reports in Neurology}

Case Rep Neurol 2020;12:56-62

\begin{tabular}{l|l} 
DOI: 10.1159/000506974 & $\odot 2020$ The Author(s). Published by S. Karger AG, Basel \\
\hline
\end{tabular} www.karger.com/crn

Nguyen et al.: Endovascular Treatment in a Patient with Large Ischemic Core and Dramatic Recovery

endovascular procedure. She had a dramatic recovery with an NIHSS score of 4 at 24 -h after the procedure. She was discharged on day 9 with a modified Rankin Score of 1 . Our findings suggest that endovascular treatment can be beneficial to the patients, particularly younger ones, with large ischemic cores with the aid of perfusion imaging.

\section{Introduction}

Multiple studies demonstrated that acute ischemic stroke (AIS) patients with a large core volume (irreversibly damaged tissue), usually $\geq 70 \mathrm{~mL}$, had a low rate of favorable outcomes, ranging from 0 to 21\% [1]. A recently Multiple Endovascular Stroke Trials (HERMES) metaanalysis suggests that the rate of symptomatic hemorrhagic transformation is increased in stroke patients with a large core volume who underwent mechanical thrombectomy (MT) [2]. Endovascular intervention (EVT), which has been proven to be the most effective treatment in the acute phase of stroke with large artery occlusion, was deemed futile for patients with large infarct core. A core volume greater than $70 \mathrm{~mL}$ was considered to be an exclusion criterion for reperfusion therapy in most clinical trials. However, this concept came from the studies conducted in patients receiving intravenous thrombolysis whereby a higher rate of symptomatic intracerebral hemorrhage and poorer outcomes can be attributable to malignant profile [1]. Recently, there has been some evidence that patients who present within $6 \mathrm{~h}$ with a core volume $\geq 70 \mathrm{~mL}$ may still benefit from EVT, which was potentially related to high reperfusion rates observed in these studies [3]. The SELECT study suggests that there are potential benefits for patients with large cores up to $24 \mathrm{~h}$ from the time last known to be well, who were selected based on an Alberta Stroke Program Early CT Score (ASPECTS) of less than 6, or a volume with a relative cerebral blood flow $<30 \%$ of $\geq 50 \mathrm{~cm}^{3}$ on CT perfusion scanning [4]. We present a case of MT in a patient with a large ischemic core who showed dramatical recovery [5].

\section{Case Presentation}

We reported a case of late-presenting and progressing AIS successfully undergoing endovascular thrombectomy. Our patient is a 55-year-old female presenting at our hospital with left hemiparesis and headache. Upon hospitalization at our center at 15:30, it was more than $16 \mathrm{~h}$ since she was last seen well at 23:00 the day before going to sleep. Her admission NIHSS score was 7, with only mild left-sided hemiparesis and paresthesia. Subsequent non-contrast computed tomography (NCCT) revealed a large infarction core and an Alberta stroke program early CT score (ASPECTS) of 5 (Fig. 1a). Her past medical history was uncertain with only unknown valvulopathy noted. A computed tomography angiography was later performed, which revealed an occlusion site at the proximal segment of the right middle cerebral artery. During the imaging procedure, her clinical status worsened with severe left hemiparesis and an increased NIHSS score from 7 to 15 . We decided to obtain a perfusion-weighted MRI scan, using RAPID software to determine the salvageable zone. Core volume (as defined by an apparent diffusion coefficient threshold less than $620 \times 10^{-6} \mathrm{~mm}^{2} / \mathrm{s}$ ) was estimated to be $88 \mathrm{~mL}$ and mismatch volume (as defined by a $\mathrm{T}_{\max }>6 \mathrm{~s}$ volume subtracted by the core volume) was 43 mL (Fig. 2a). We then decided to perform MT with the consent of her family. During the 2-h 


\section{Case Reports in Neurology}

Case Rep Neurol 2020;12:56-62 DOI: $10.1159 / 000506974$

(c) 2020 The Author(s). Published by S. Karger AG, Basel www.karger.com/crn

Nguyen et al.: Endovascular Treatment in a Patient with Large Ischemic Core and Dramatic Recovery

procedure, we managed to remove multiple small thrombi after five attempts using the Solitaire stent retriever and eventually achieved TICI-3 recanalization. NCCT was repeated the next day which showed cerebral hemorrhage of parenchymal hematoma type 1 (PH1). At 24-h check-up, her neurological functions recovered remarkably with an NIHSS score of 4. On day 4, perfusion imaging was repeated to estimate the final infarct core volume (Fig. 2b). On day 6, NCCT was repeated showing extended infarct and a quick absorption of cerebral hemorrhage (Fig. 1b). The etiology of her stroke remains uncertain in the absence of large vessel atherosclerosis on vascular imaging, though an embolism was suspected. We decided to start clopidogrel, rosuvastatin, and perindopril. On day 9, she was discharged with an NIHSS score of 3.

\section{Discussion}

Currently, there is no evidence on the treatment of AIS patients with large ischemic cores, often defined as an ASPECTS $<6$ or an ischemic core volume greater than $50-70 \mathrm{~mL}$. A recent meta-analysis of individual participant data of five major thrombectomy trials did not observe treatment benefits in patients with an ASPECTS of 5 or less [2]. However, with advanced imaging selection, EVT may be beneficial in patients with large infarct core on MRI-DWI or perfusion CT [6]. Although the patient was not fulfilling inclusion criteria of both DAWN and DEFUSE 3 (ASPECTS $<6$, cores $>70 \mathrm{~mL}$, mismatch ratio $<1.8$ ), she did have a relatively large penumbra. Her absolute mismatch volume was $43 \mathrm{ml}$, which was larger than the minimum 15 $\mathrm{mL}$ required by DEFUSE 3, and fulfilled mismatch criteria of other trials (e.g., EXTEND-IA which required a mismatch $>10 \mathrm{~mL}$ and mismatch ratio $>1.2$ ) [7-9]. Proper patient selection is therefore critical, and advanced imaging techniques have been developed to identify those who can benefit from reperfusion treatment [6]. There was no significant difference in major intracranial hemorrhage in the SELECT study. Moreover, hemicraniectomy and 90-day mortality rates were lower in the endovascular treatment group [10]. They suggested EVT was relatively safe. Other studies showed that young acute stroke patients who have a large ischemic core and large mismatch imaging profile might still benefit from EVT $[6,11]$. On the contrary, patients older than 75 years have a higher risk of poor outcomes with EVT [6]. Although the follow-up NCCT and MRP (perfusion-weighted MRI) showed extended infarct, saving 15-20 mL of the penumbra can make an important effect in improving outcomes. Therefore, this case suggests that in young large-vessel occlusion patients presenting in a late time window with a large infarct core, endovascular therapy could still be considered on a case-bycase basis. Our decision was based on the patient's large mismatch volume (43 mL) and younger age $(<60$ years old $)$.

\section{Acknowledgment}

Dr. Tra S.V. Le interpreted the images, treated the patient, and provided patient data.

\section{Karger'}




\section{Case Reports in Neurology}

\section{Statement of Ethics}

Written informed consent was obtained from the patient for publication of this case report and any accompanying images.

\section{Conflict of Interest Statement}

The authors have no conflicts of interest to declare.

\section{Funding Sources}

The author received no financial support for the research, authorship, and publication of this article.

\section{Author Contributions}

Trung Q. Nguyen was a major contributor in writing the manuscript and performing the literature review. Tinh Q. Dang and Hoang T. Phan made major contributions to the interpretation and revision of the manuscript. Thang H. Nguyen supervised the study, interpreted the patient data, and was a major contributor in writing the manuscript. All authors read and approved the final manuscript.

\section{References}

1 Albers GW, Thijs VN, Wechsler L, Kemp S, Schlaug G, Skalabrin E, et al.; DEFUSE Investigators. Magnetic resonance imaging profiles predict clinical response to early reperfusion: the diffusion and perfusion imaging evaluation for understanding stroke evolution (DEFUSE) study. Ann Neurol. 2006 Nov;60(5): 508-17.

2 Goyal M, Menon BK, van Zwam WH, Dippel DW, Mitchell PJ, Demchuk AM, et al.; HERMES collaborators. Endovascular thrombectomy after large-vessel ischaemic stroke: a meta-analysis of individual patient data from five randomised trials. Lancet. 2016 Apr;387(10029):1723-31.

3 Chen Z, Zhang R, Zhou Y, Gong X, Zhang M, Shi F, et al. Patients with ischemic core $\geq 70 \mathrm{ml}$ within $6 \mathrm{~h}$ of symptom onset may still benefit from endovascular treatment. Front Neurol. 2018 Nov; 9:933.

4 Sarraj A, Hassan AE, Savitz S, Sitton C, Grotta J, Chen P, et al. Outcomes of endovascular thrombectomy vs medical management alone in patients with large ischemic cores: a secondary analysis of the optimizing patient's selection for endovascular treatment in acute ischemic stroke (SELECT) Study. JAMA Neurol. 2019 Jul 29;76(10):1147-56.

5 Mazighi M, Meseguer E, Labreuche J, Serfaty JM, Laissy JP, Lavallée PC, et al. Dramatic recovery in acute ischemic stroke is associated with arterial recanalization grade and speed. Stroke. 2012 Nov;43(11):29983002.

6 Rebello LC, Bouslama M, Haussen DC, Dehkharghani S, Grossberg JA, Belagaje S, et al. Endovascular treatment for patients with acute stroke who have a large ischemic core and large mismatch imaging profile. JAMA Neurol. 2017 Jan;74(1):34-40.

7 Nogueira RG, Jadhav AP, Haussen DC, Bonafe A, Budzik RF, Bhuva P, et al.; DAWN Trial Investigators. Thrombectomy 6 to 24 hours after stroke with a mismatch between deficit and infarct. N Engl J Med. 2018 Jan;378(1):11-21.

8 Albers GW, Marks MP, Kemp S, Christensen S, Tsai JP, Ortega-Gutierrez S, et al.; DEFUSE 3 Investigators. DEFUSE 3 Investigators. Thrombectomy for stroke at 6 to 16 hours with selection by perfusion imaging. N Engl J Med. 2018 Feb;378(8):708-18.

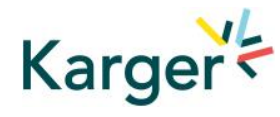


Case Reports in Neurology
Case Rep Neurol 2020;12:56-62

DOI: 10.1159/000506974

C) 2020 The Author(s). Published by S. Karger AG, Basel www.karger.com/crn

Nguyen et al.: Endovascular Treatment in a Patient with Large Ischemic Core and Dramatic Recovery

9 Campbell BC, Mitchell PJ, Kleinig TJ, Dewey HM, Churilov L, Yassi N, et al.; EXTEND-IA Investigators. Endovascular therapy for ischemic stroke with perfusion-imaging selection. N Engl J Med. 2015 Mar;372(11):1009-18.

10 Mohan Rajwani K, Crocker M, Moynihan B. Decompressive craniectomy for the treatment of malignant middle cerebral artery infarction. Br J Neurosurg. 2017 Aug;31(4):401-9.

11 Kakita H, Yoshimura S, Uchida K, Sakai N, Yamagami H, Morimoto T, et al.; RESCUE-Japan Registry 2 Investigators. Impact of endovascular therapy in patients with large ischemic core: subanalysis of recovery by endovascular salvage for cerebral ultra-acute embolism Japan Registry 2. Stroke. 2019 Apr;50(4):901-8. 
Case Reports in Neurology

\begin{tabular}{l|l}
\hline Case Rep Neurol 2020;12:56-62 \\
\hline DOI: 10.1159/000506974 & $\begin{array}{l}\text { @ 2020 The Author(s). Published by S. Karger AG, Basel } \\
\text { www.karger.com/crn }\end{array}$ \\
\hline
\end{tabular}

Nguyen et al.: Endovascular Treatment in a Patient with Large Ischemic Core and Dramatic Recovery

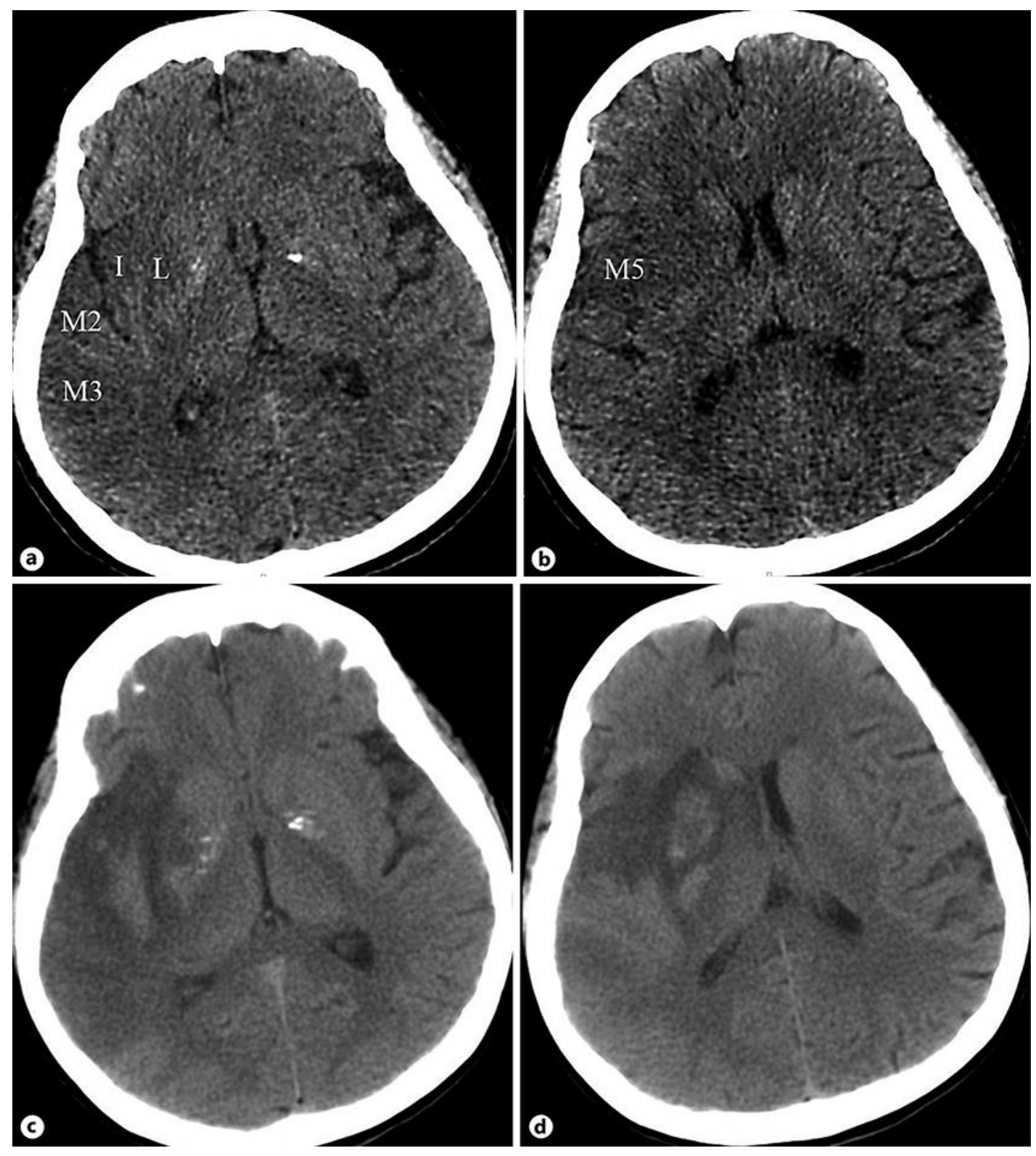

Fig. 1. The initial NCCT showed a low ASPECTS score of $5(\mathbf{a}, \mathbf{b})$. On day 6 , NCCT was repeated showing a change in infarct size after EVT and a quick absorption of cerebral hemorrhage (c, d). L, lentiform nucleus; I, insular cortex. 
Case Reports in Neurology
Case Rep Neurol 2020;12:56-62

DOI: $10.1159 / 000506974$ (c) 2020 The Author(s).
www.karger.com/crn

Nguyen et al.: Endovascular Treatment in a Patient with Large Ischemic Core and Dramatic Recovery
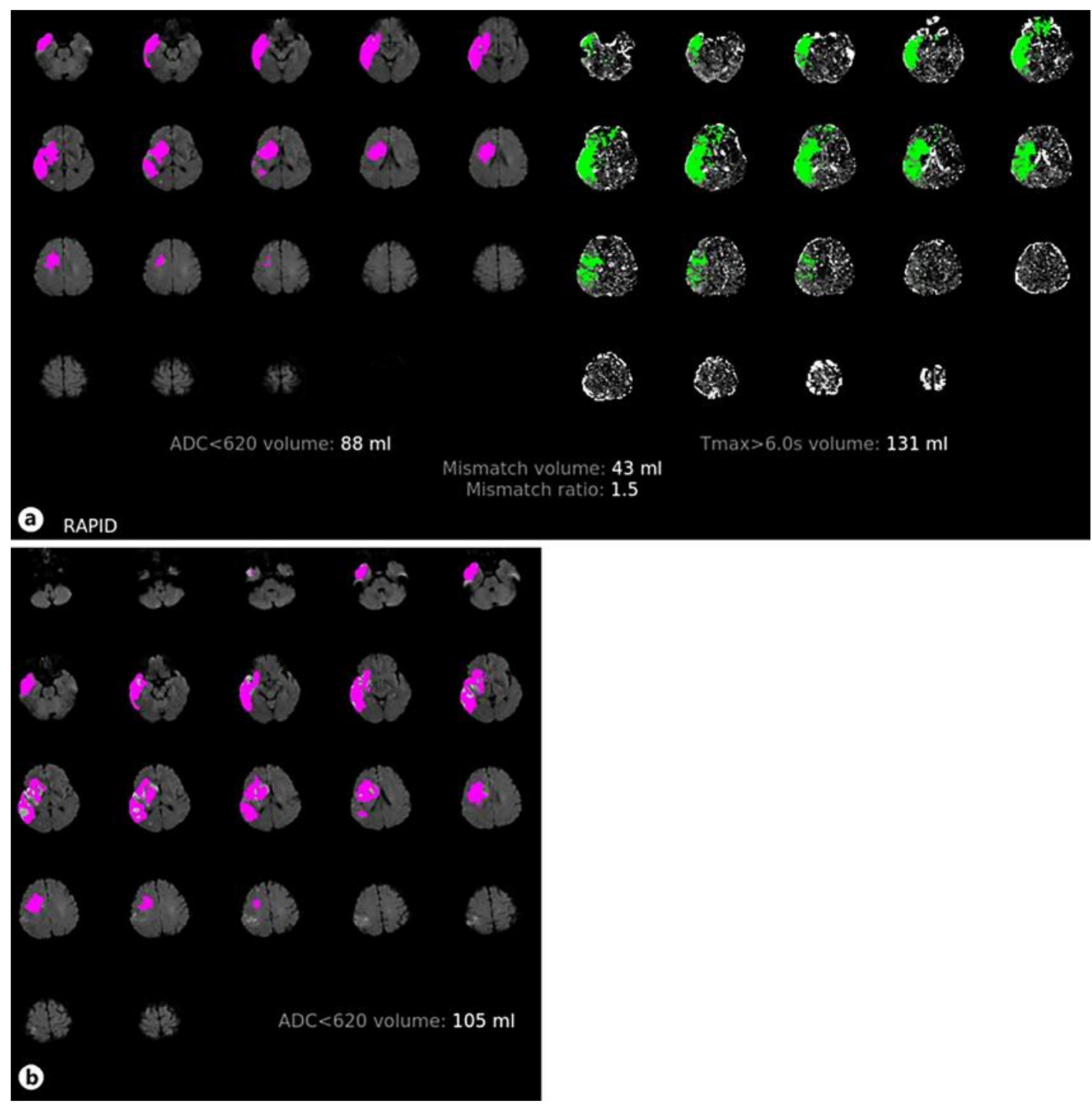

Fig. 2. Perfusion magnetic resonance imaging with RAPID software showed a large mismatch volume (a). Perfusion imaging was repeated to estimate the final infarct core volume (b), demonstrating that $26 \mathrm{~mL}$ of the penumbra was saved. 